\title{
Self-Healing Metals and Metal Matrix Composites
}

\author{
J.B. FERGUSON ${ }^{1}$ BENJAMIN F. SCHULTZ, ${ }^{1,2}$ \\ and PRADEEP K. ROHATGI ${ }^{1}$ \\ 1.-Materials Science and Engineering Department, University of Wisconsin-Milwaukee, \\ Milwaukee, WI 53201, USA. 2.—e-mail: bfs2@uwm.edu
}

Self-healing in inorganic materials is a relatively new area in materials science and engineering that draws inspiration from biological systems that can self-repair damage. This article reviews the preliminary attempts to impart self-healing behavior to metals. Several challenges yet exist in the development of metallic alloys that can self-repair damage, including surface bonding issues, such as liquid/solid contact angle (wetting) and oxidation, and practical issues, such as capillary pressure for delivery of a liquid metal to a damaged area or crack, and the overall mechanical properties of a composite system. Although the applied research approaches reviewed have obtained marginal success, the development of self-healing metallic systems has the potential to benefit a wide range of industrial applications and thus deserves greater investment in fundamental research.

\section{INTRODUCTION}

To create self-healing metallic materials is a daunting task. Due to the high melting temperatures of metals, repair processes must take place at high temperatures or in specialized environments. The reactive nature of metals with oxygen and water further complicates metallic joining as rapidly formed oxides at surfaces make bonding difficult. However, several methods are currently being developed to provide self-healing properties to metallic and metal matrix composite systems. These include solid state methods such as precipitation healing, semisolid state methods incorporating shape memory alloys, vascular networks filled with reactive low melting alloys, as well as liquid state methods such as electroplating.

The development of materials with self-repairing properties inspired by nature into inorganic systems is garnering growing interest from materials scientists. Although there have been significant advances in self-healing polymers ${ }^{1}$ and ceramics, ${ }^{2}$ progress in self-healing metals has been rather limited. Selfhealing methods for metallic systems cannot be copied directly from the natural systems that inspire them, posing several particularly vexing challenges. Living systems generate healing agents, transport them to the site of damage, and then use them to repair the injury. Metallic healing, on the other hand, is often accomplished using methods similar to welding or joining, which requires the melting of the metal to be joined or the introduction of new liquid metal. In systems that make use of electroplating-like techniques, the component must be surrounded by liquid solutions of specific chemical compositions. Even solid state methods require an elevated temperature and considerable time to produce healing. Unlike ceramic or polymer-based materials, oxidation further complicates metallic joining as fresh metal oxidizes when exposed to air or water, making bonding difficult. Due to the high melting temperatures of metals, these types of repair processes must take place at significantly higher temperatures than in polymer or ceramic self-healing systems. Notwithstanding these challenges, there has been some progress in the development of self-healing metals.

\section{SELF-HEALING TECHNIQUES}

\section{Precipitation Healing}

A precipitation hardenable alloy possesses decreasing solubility of the solute element with decreasing temperature. Therefore, upon solidification, the alloy changes from liquid to a single solid phase and then two solid phases upon solidification. If the two-phase solid is reheated to a temperature at which only the single phase material is stable, 
the material can enter a metastable state if quenched rapidly from this high temperature, where the alloy has become supersaturated with solute. Subsequent precipitation heat treatments conducted at lower temperatures where the two-phase solid is stable will result in solute precipitation and produce three distinct stages or material conditions: (I) underaged-copious, fine precipitates coherent with the matrix, (II) peak-aged-precipitates bordering on incoherency, and (III) overaged-fewer, coarse precipitates incoherent with the matrix. Precipitates tend to form at high-stress/high-energy regions such as voids and areas of high dislocation density. Dislocations and voids tend to concentrate in regions of high stress eventually causing cracks. Because precipitate nucleation and growth will more likely occur in these regions as well, crack growth can be retarded or reversed to a degree providing some measure of healing. In other words, open-volume defects, such as vacancies, vacancy clusters, and dislocations, facilitate the diffusion of solutes and thereby accelerate precipitation, which promotes the self-healing of metals by dynamic precipitation. Crack growth can therefore be retarded or reversed; this has been shown by Lumley $^{3}$ in an underaged $\mathrm{Al}-\mathrm{Cu}-\mathrm{Mg}-\mathrm{Ag}$ alloy following 500 -h creep at $300 \mathrm{MPa}$ and $150^{\circ} \mathrm{C}$. The method has also been employed by Djugum et al. ${ }^{4}$ in $\mathrm{Al}-\mathrm{Cu}$ Alloy AA2001. Figure 1 shows the sequence of healing of an aluminum copper alloy that under-
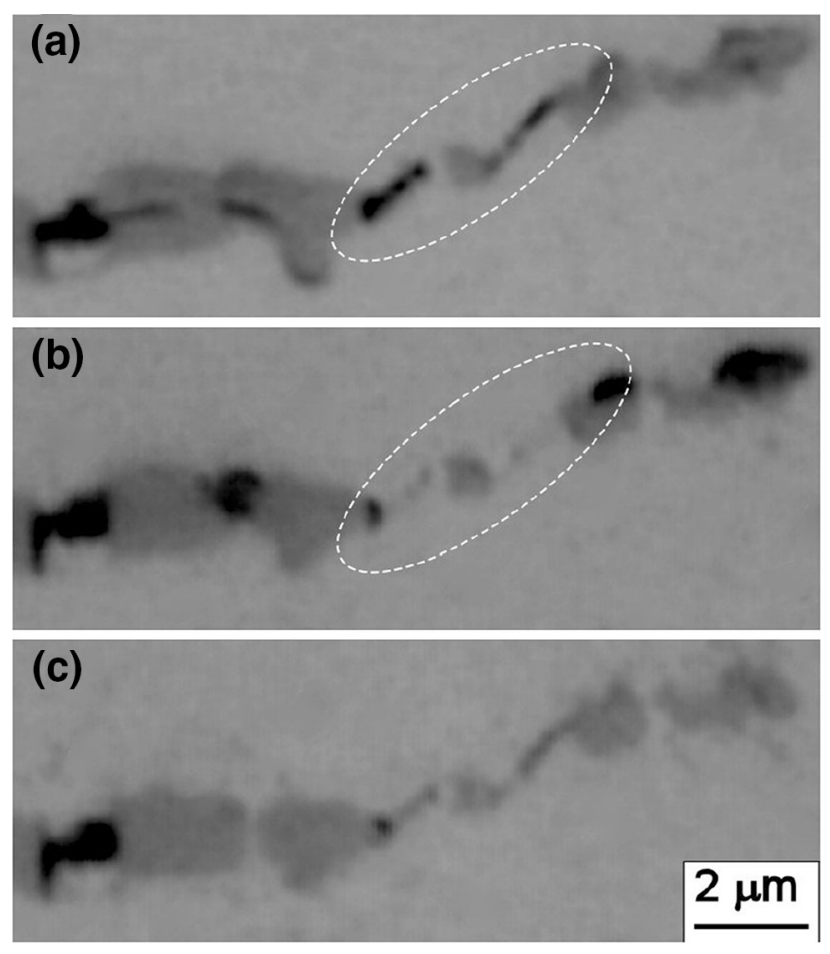

Fig. 1. Micrographs of an Al-Cu AA2001 alloy specimen underaged at $180^{\circ} \mathrm{C}$ for $4 \mathrm{~h}$ and tensile tested. (a) Cracks at the sites of two fractured $\mathrm{Al}-\mathrm{Cu}$ intermetallic compounds, (b) crack closure after further aging, and (c) pore fragmentation. went aging heat treatments after being underaged and then tested in such a way as to produce a crack.

He et al. ${ }^{5}$ have reported that creep damage can be healed in austenitic stainless steels containing boron and copper by dynamic precipitation of these elements from the supersaturated matrix. In their studies, creep resistance was significantly improved when precipitates partially filled nanoscale openvolume defects and thereby prevented further spread of damage. They compared the precipitation kinetics in deformed $\mathrm{Fe}-\mathrm{Cu}$ and $\mathrm{Fe}-\mathrm{Cu}-\mathrm{B}-\mathrm{N}$ alloys by positron annihilation spectroscopy, and their results suggest that open-volume defects introduced by plastic deformation in pure $\mathrm{Fe}$ can be recovered almost completely by self-diffusion of $\mathrm{Fe}$ atoms during the aging step and that this behavior is independent of the heat treatment before testing. Their tests on $\mathrm{Fe}-\mathrm{Cu}$ alloys also indicate that $\mathrm{Cu}$ precipitation is promoted by the presence of dislocations. In related studies, the researchers concluded that due to properties of the various alloys, self-healing with Fe-Cu-B-N alloys will initially take place by the formation of $\mathrm{BN}$ precipitates, and may be assisted by copper precipitation when larger creep cavities are formed.

\section{Shape Memory Alloy-Based Healing}

This technique employs micron-size shape memory alloy (SMA) wires to pull together a crack and then bonds the damaged surfaces together using a partial melting technique. SMAs are materials that will revert to a "trained" shape upon the application of heat due to phase changes involving two phases known as austenite and martensite. The SMA transforms from the martensite to the austenite phase upon heating, and back to the martensite phase upon cooling. In the martensite state, the SMA can be easily deformed, responding to stress by "twinning" or changing the orientation of its crystal structure. ${ }^{6,7}$ In self-healing situations, SMA wires embedded in a metallic system revert from martensite to austenite upon heating to achieve crack closure. If the wires embedded in the sample have been prestrained, then a clamping force is exerted on the damaged material.

Matrix materials used in these types of systems to date have all been off-eutectic alloys. Off-eutectic alloys have markedly different solidus and liquidus temperatures, and between these temperatures, an off-eutectic alloy exists as a semisolid paste of solid particles surrounded by molten liquid above a certain temperature. The amount of molten material can be controlled by heating to a specified temperature. Tin and bismuth form one such binary eutectic with a low melting point of $139^{\circ} \mathrm{C}$ that has been investigated in SMA-based healing studies by Manuel and Olsen. ${ }^{8} 9$ A damaged sample can be healed when the temperature of the system is elevated to a point at which the SMA wires attempt to return to their original configuration, and clamp the 


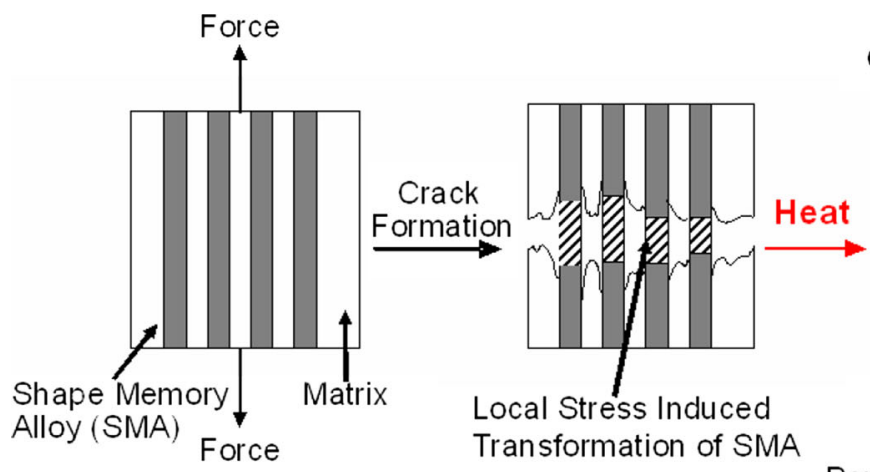

\section{Crack Closure}

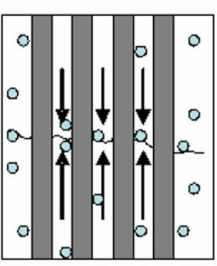

Post Heating:

Reversion of SMA

Partial Matrix Liquefaction

Fig. 2. Schematic overview of the self-healing process in metal/SMA composite. ${ }^{8}$
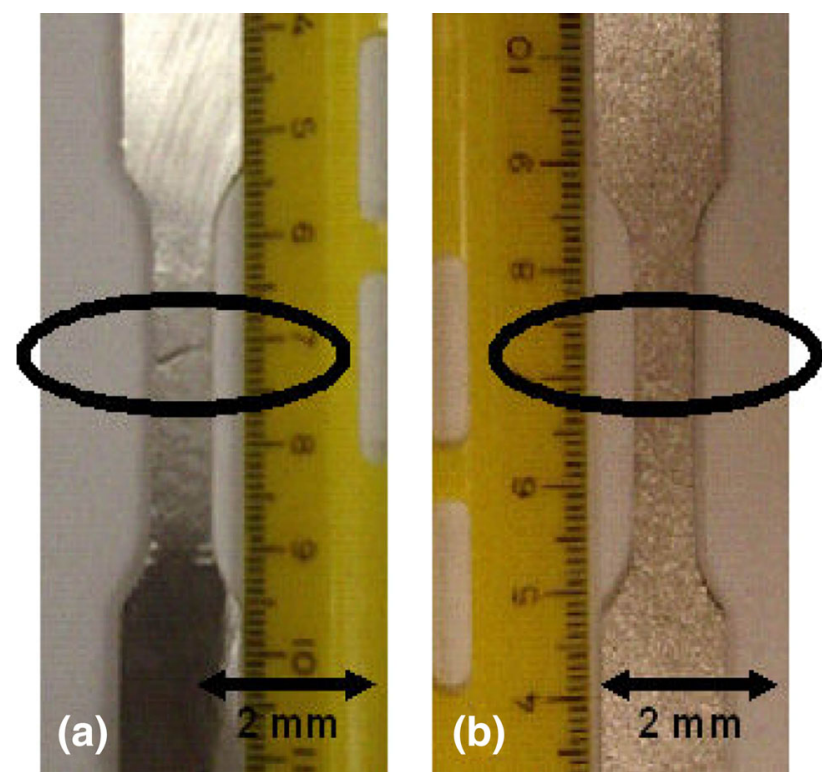

Fig. 3. Self-healing Sn-Bi/SMA composite: (a) demonstration of a prehealed composite with a through matrix crack and (b) demonstration of a healed composite. ${ }^{8}$

damaged surfaces together. As the healing temperature is between the solidus and liquidus temperatures, the material partially melts while leaving enough solid to maintain the structural integrity of the system. The liquid at each surface can then flow or otherwise bridge the gap created by the damage and upon cooling resolidify, thus, healing the system. The overall process is shown in Fig. 2.

Manuel and Olson ${ }^{8}$ fabricated a Sn-based selfhealing proof-of-concept composite using a Sn13at.\%Bi matrix and NiTi SMA wires. The SMA wire reinforcements were continuous and uniaxially oriented with a volume fraction of $1 \%$ in the matrix. Prior to casting, the wires were sputter coated with $5 \mathrm{~nm}$ of gold to increase the wettability of the wire surface. Tensile tests were performed to assess the mechanical behavior of the composite and matrix alloys. The composite displayed a $73 \%$ increase in uniform ductility in comparison with the unreinforced prototype alloy due to composite toughening: improving from
$3.7 \%$ to $6.4 \%$, which was attributed to either grain refinement of the alloy due to the presence of the SMA reinforcement or interfacial debonding or crack bridging along the matrix/reinforcement interface.

To demonstrate healing efficiency, tensile tests were performed on the composites at room temperature until complete matrix failure. After failure, the specimens were removed from the tensile testing apparatus and heat-treated at $169^{\circ} \mathrm{C}$ for $24 \mathrm{~h}$ in vacuum to heal the crack. After crack healing, the specimens were again tensile tested to failure to determine the amount of strength recovery, which achieved greater than $95 \%$ of the original composite ultimate tensile strength. However, this was offset by a reduction in uniform ductility from $6.4 \%$ to $2.2 \%$ attributed to defects that accumulated at the crack surface during healing, including voids, oxides, and brittle eutectic phases. Samples prior to the healing cycle and post-healing cycle are displayed in Fig. 3.

Manuel $^{9}$ expanded their SMA work on Sn-Bi alloys with a magnesium-based cast alloy. They designed a high specific strength solution-treated $\mathrm{Mg}-5.7$ at.\% $\mathrm{Zn}-2.7$ at.\% $\mathrm{Al}$ proof-of-concept self-healing alloy composite reinforced with $1 \%$ volume fraction of commercial $\mathrm{Ti}-49.4$ at. $\%$ Ni SMA wires. A $160 \%$ increase in uniform ductility resulted in composite toughening in the specimen. They treated their matrix to increase its strength by $40 \%$ over commercial cast magnesium AZ91 alloy and heated their SMA wires for $3 \mathrm{~h}$ at $500^{\circ} \mathrm{C}$ to increase their transformation temperatures.

The group found that as the SMA wires pulled the crack closed, the rough crack walls came into contact and prevented full closure. Unlike in the Sn-Bi matrix composite, the force applied by the SMA wires could not overcome the matrix strength of the Mg-based alloy. Poor wetting of the reinforcement and low strength of the interface was also identified as deleterious to the performance of the composite.

\section{Composite Materials Reinforced with a Healing Agent}

A self-healing composite can also be synthesized by delivering a low-melting temperature alloy to the 

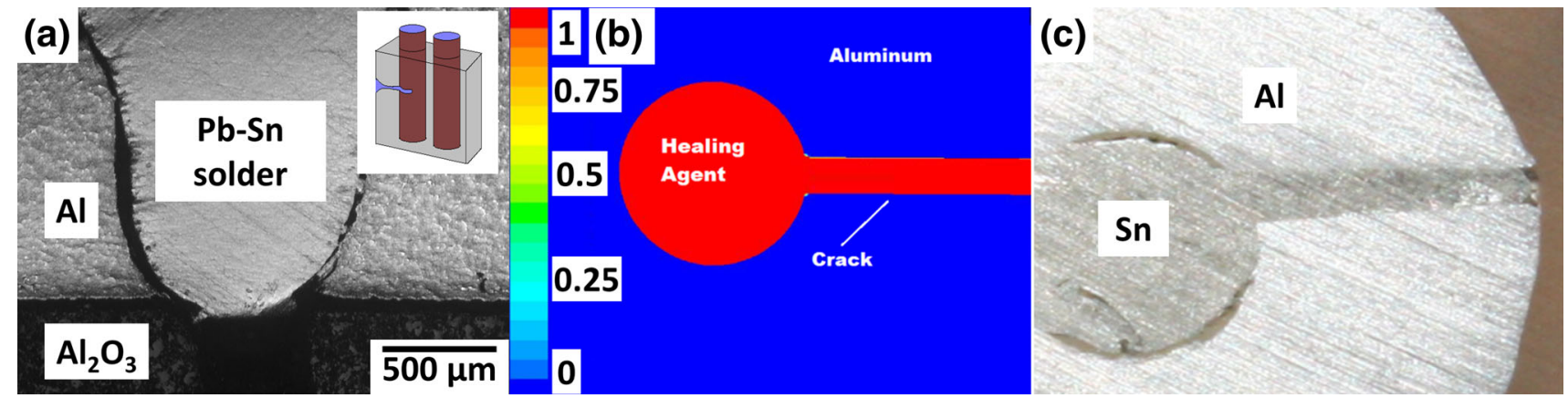

Fig. 4. Examples of composite materials reinforced by a healing agent: (a) interface between Al-A206 matrix and Pb-Sn solder self-healing composite after high-temperature healing treatment (inset shows a schematic of the composite where the solder was encapsulated in $\mathrm{Al}_{2} \mathrm{O}_{3}$ tubes and embedded in an A206 matrix; ${ }^{14}$ (b) computational fluid dynamic (CFD) modeling of Sn encased in aluminum flowing into a simulated crack upon heating; and (c) experimental verification of the CFD model.

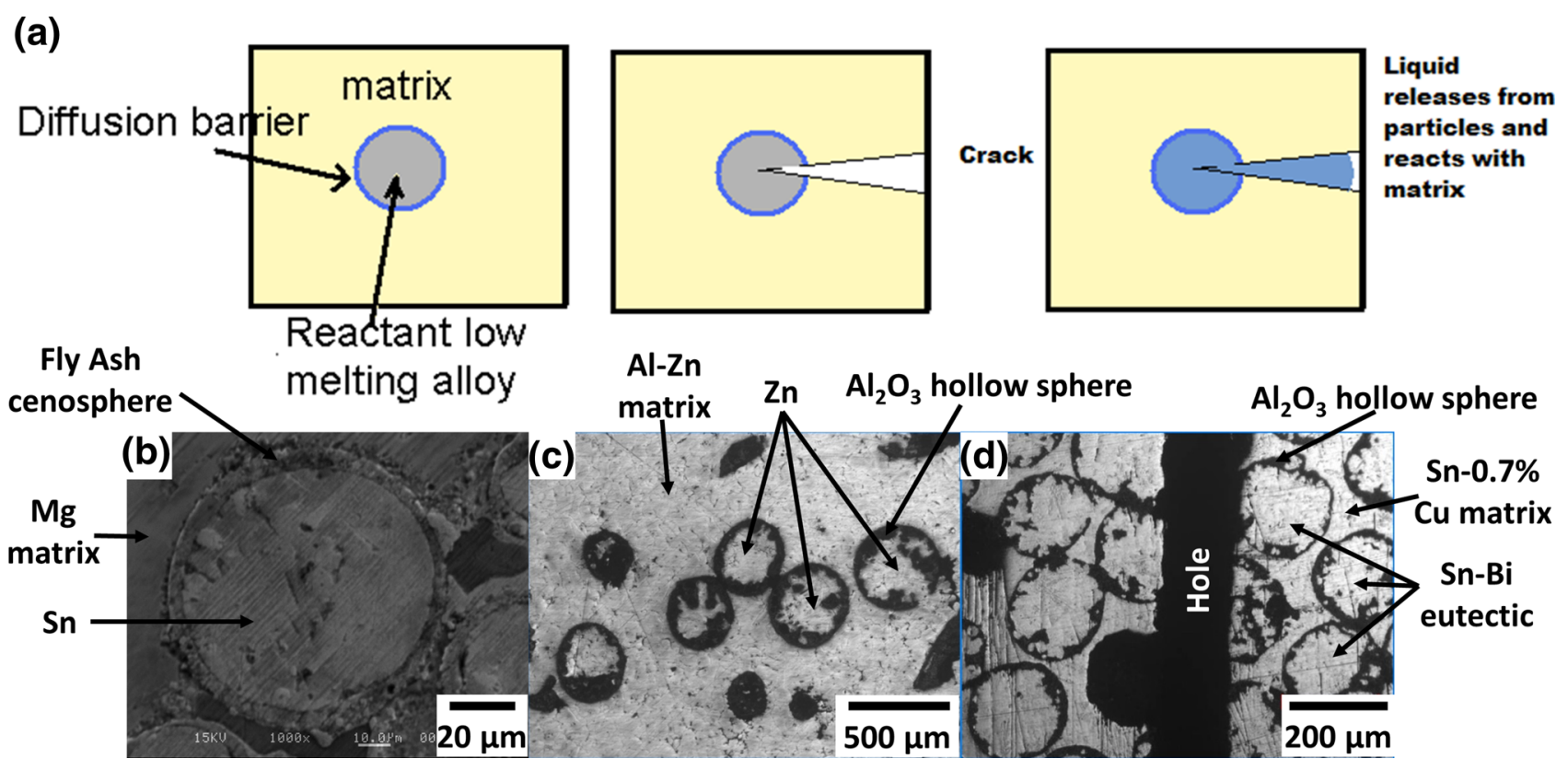

Fig. 5. Examples of composite materials reinforced by a healing agent contained in hollow ceramic spheres: (a) schematic of self-healing metal incorporating an encapsulated low melting metal inside a higher melting point metal matrix; (b) SEM image of Sn-filled fly ash cenosphere embedded in $\mathrm{Mg}$ matrix by pressure infiltration; (c) optical micrsostructure of $\mathrm{Zn}$-filled $\mathrm{Al}_{2} \mathrm{O}_{3}$ hollow spheres embedded in Al-Zn matrix by stir casting; and (d) optical microstructure of $\mathrm{Sn}$-Bi-eutectic-filled $\mathrm{Al}_{2} \mathrm{O}_{3}$ hollow spheres embedded in $\mathrm{Sn}-0.7 \%$ Cu matrix by pressure infiltration. A hole has been drilled into the sample to simulate a crack extending through multiple low-melting-point-metal-filled spheres. Heating can cause the $\mathrm{Sn}-\mathrm{Bi}$ eutectic to melt and flow out into the hole.

damaged region that serves as a healing agent in a high-melting temperature alloy metal matrix composite. ${ }^{10-13}$ Lucci et al. ${ }^{14-17}$ studied a composite consisting of an $\mathrm{Al}$ alloy 206 matrix reinforced with hollow ceramic tubes whose hollow spaces were infiltrated with a lower melting point $\mathrm{Sn}-40 \mathrm{~Pb}$ solder. A hole was drilled to simulate the crack in the metal matrix running into the microtube. The sample was then heated above the melting point of the alloy, held for $5 \mathrm{~min}$, and cooled to room temperature. The solder flowed out of the microtubes and sealed the hole as shown in Fig. 4a. This method has so far proved challenging to perfect and needs further work. In experiments done so far, cracks can be sealed only partially, and the bond between the aluminum and the solder has high interfacial porosity, indicating that the interfacial bonding between the healing agent and the matrix is poor. Lucci et al. ${ }^{14-17}$ have also done computational fluid dynamic simulation to estimate the widths and orientations of the cracks that can be healed. An example of a typical simulation result is shown in Fig. $4 \mathrm{~b}$, where the healing agent is predicted to flow into a crack of a certain geometry and orientation in relation to the healing agent reservoir as demonstrated experimentally in Fig. 4c. 

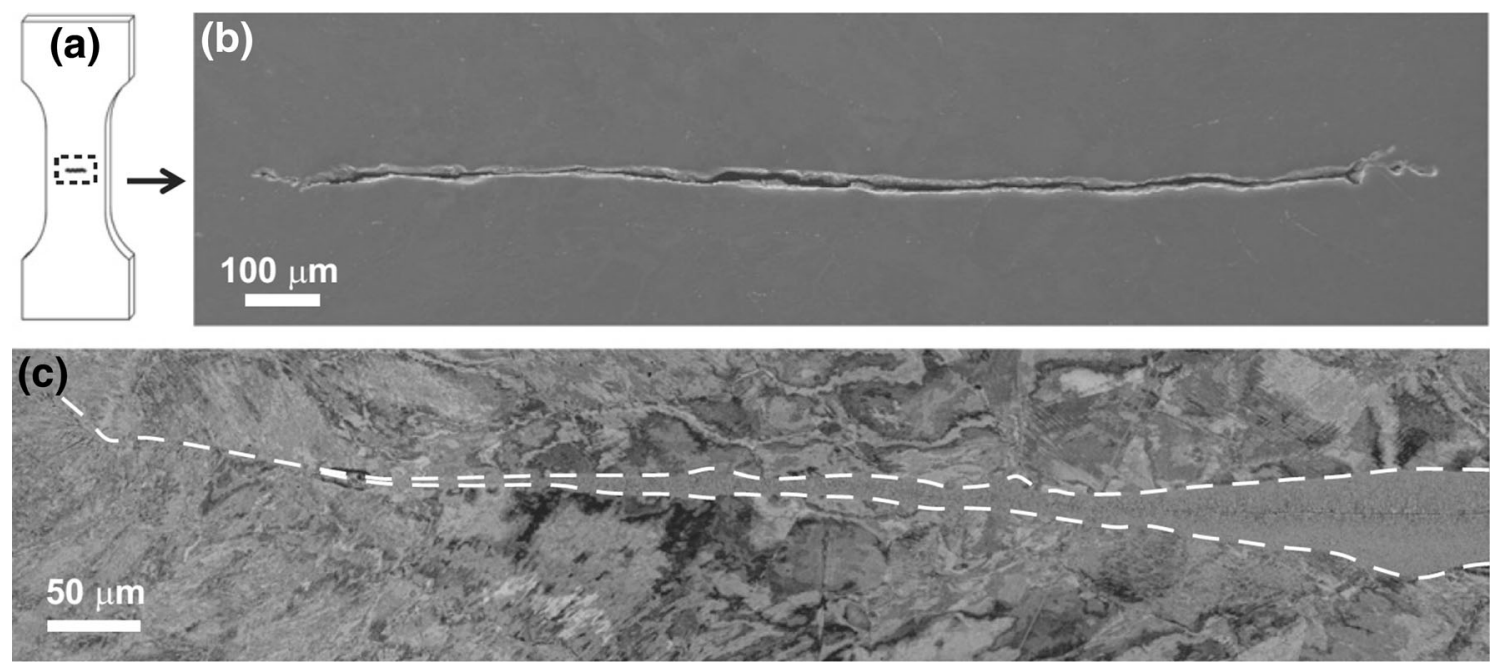

Fig. 6. (a) Location of crack in tensile sample, (b) crack in Ni before healing, and (c) healed crack. ${ }^{18}$

Efforts have also been undertaken to encapsulate a low melting point metal in hollow microspheres that can act as a barrier between the low melting point metal and a higher melting point alloy during casting. Figure 5 shows several such potential structures in different matrices. Proper diffusion barrier materials and low melting point metals must be chosen to ensure that (I) cracks bridge through the wall material exposing the healing agent and (II) the healing agent bonds with the matrix once they are in contact.

\section{Electrochemical Healing}

Zheng et al. ${ }^{18}$ have investigated electrochemical healing of Ni using an electroplating approach. In their work, samples of $99.84 \%$ pure polycrystalline $\mathrm{Ni}$ with prefabricated cracks were cleaned in sulfuric/phosphoric acid solutions and submersed in a high throwing power plating solution consisting of various combinations of $\mathrm{NiSO}_{4}, \mathrm{NiCl}_{2}$, and $\mathrm{HBO}_{3}$ and electrohealed for several hours. Healing temperatures were varied for samples of differing thickness, where $40^{\circ} \mathrm{C}$ was used for thin samples and $55^{\circ} \mathrm{C}$ for thicker samples. Figure 6 shows that the crack can be filled and that the healing material is deposited epitaxially from each side of the crack. In the center of the crack, the growing films meet, forming a structure similar to a parting line that is solid at the crack edges and in the wider regions but has some microporosity in narrower regions. Uniaxial tensile tests in $100-\mu \mathrm{m}$-thick specimens showed that uncracked samples had an ultimate tensile strength (UTS) of $412 \mathrm{MPa}$, while the UTS of the healed sample had a UTS of $394 \mathrm{MPa}$-both considerably higher than the 249-MPa UTS of cracked samples. The recovered strength decreased with increasing sample thickness and approached the UTS of the cracked samples in the thickest

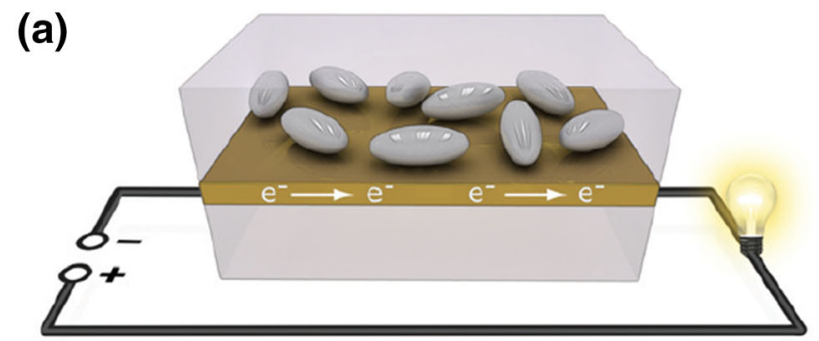

(b)

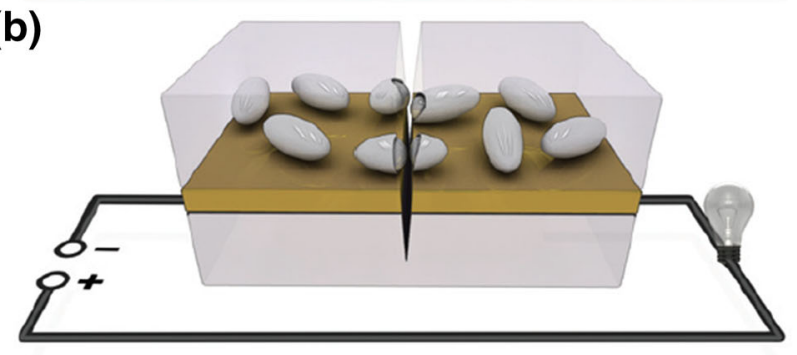

(c)

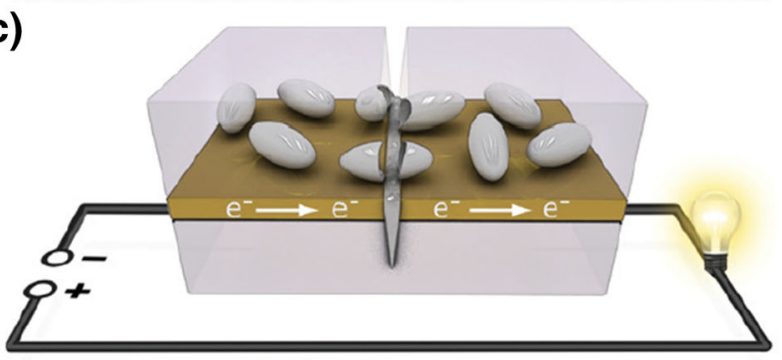

Fig. 7. Schematic of the self-healing process in solder employing liquid-metal-filled capsules. ${ }^{19}$

samples. Compared with the uncracked specimens, toughness (as measured by area under the stressstrain curve) was lower in healed specimens but considerably higher than in the cracked samples. 


\section{Self-Healing Solder}

Blaiszik et al. ${ }^{19}$ have shown that it is possible to reestablish electrical contact in a broken conductor using polymeric capsules containing a eutectic GaIn alloy embedded in solder. Figure 7 shows schematically how the cracks that can form in solders due to mechanical damage (e.g., fatigue cracks resulting from thermal cycling) rupture the capsules and allow Ga-In liquid to flow into the damaged region. Reactions between Ga-In and atmospheric $\mathrm{O}_{2}$ form a solid passivating oxide that provides structural integrity to the healed circuit. The system has been shown to recover more than $99 \%$ of precrack conductivity and to retain this conductivity for the several months that it was monitored. Healing time was approximately $160 \mu \mathrm{s}$ and can be achieved with very low concentrations of capsules.

\section{SUMMARY}

Self-healing in inorganic materials is a relatively new area in materials science and engineering. Inspired by nature and modern technological tools, researchers are attempting to impart the ability of engineered materials to self-repair. The approaches reviewed are preliminary attempts. Work in this area continues because self-healing can be potentially extremely beneficial for a wide range of industrial applications. The research discussed in this review points to several specific challenges facing the development of self-healing metallic systems, including improving wetting, overcoming oxidation, providing sufficient capillary pressure, and healing macroscopic damage, while not sacrificing strength or functionality.

\section{REFERENCES}

1. D.Y. Wu, S. Meure, and D. Solomon, Prog. Polym. Sci. 33, 479 (2008).

2. M. Madham and G. Prabhakaran, Commun. Comput. Inf. Sci. 330, 466 (2012)

3. R. Lumley, Self Healing Materials: An Alternative Approach to 20 Centuries of Materials Science, ed. S. Van der Zwaag (Dordrecht: Springer, 2007), p. 219.

4. R. Djugum, R.N. Lumley, and I.J. Polmear, 2nd International Conference on Self Healing Materials (Chicago, IL, 2009).

5. S.M. He, N.H. van Dijk, H. Schut, E.R. Peekstok, and S. van der Zwaag, Phys. Rev. B81, 094103-1 (2010).

6. L.C. Brinson, J. Intell. Mater. Syst. Struct. 4, 229 (1993).

7. D.S. Burton, X. Gao, and L.C. Brinson, Mech. Mater. 38, 525 (2006).

8. M.V. Manuel and G.B. Olson, Proceedings of the 1st International Conference on Self-Healing Materials (Noordwijik aan Zee, The Netherlands, 2007).

9. M.V. Manuel, (PhD Dissertation, Northwestern University, Evanston, IL, 2007)

10. P.K. Rohatgi, B.C. Pai, and S.C. Panda, J. Mater. Sci. 14, 2277 (1979).

11. P.K. Rohatgi, R. Asthana, and S. Das, Int. Met. Rev. 31, 115 (1986).

12. P.K. Ghosh, S. Ray, and P.K. Rohatgi, Trans. Jpn. Inst. Met. 25,440 (1984).

13. A.K. Jha and P.K. Rohatgi, J. Mater. Sci. 21, 3681 (1986).

14. J.M. Lucci, R. Amano, and P.K. Rohatgi, Proceedings of ASME Design Engineering Technical Conference 2008 DETC (ASME, NY, 2008).

15. J.M. Lucci, R. Amano, P.K. Rohatgi, and B. Schultz, Proceedings of Mechanical Congress and Exhibition, IMECE2008-68304 (2008).

16. J.M. Lucci, R. Amano, P.K. Rohatgi, and B. Schultz, Proceedings of Energy Nano08 ASME Turbo Expo, ENIC200853011 (2008).

17. J.M. Lucci, R. Amano, P.K. Rohatgi, and B. Schultz, Proceedings of ASME Design Engineering Technical Conference, DETC2008-50148 (2008).

18. X.G. Zheng, Y.-N. Shi, and K. Lu, Mater. Sci. Eng. 561, 52 (2013).

19. B.J. Blaiszik, S.L.B. Kramer, M.E. Grady, D.A. McIlroy, J.S. Moore, N.R. Sottos, and S.R. White, Adv. Mater. 24, 398 (2012). 